\title{
Desempenho e características de carcaça de tourinhos alimentados com dietas contendo silagem de bagaço de laranja substituindo a silagem de sorgo
}

\author{
Performance and carcass characteristics of young bulls fed diets with orange peel \\ silage replacing sorghum silage
}

\author{
GOBBI, Kátia Fernanda ${ }^{1 *}$; ABRAHÃO, José Jorge dos Santos ${ }^{1}$; MOLETTA, José \\ Luiz $^{2}$; SANTOS, Tiago Machado dos ${ }^{3}$; BETT, Vanderlei ${ }^{1}$; LUGÃO, Simony Marta \\ Bernardo ${ }^{1}$
}

\footnotetext{
${ }^{1}$ Instituto Agronômico do Paraná, Paranavaí, Paraná, Brasil.

${ }^{2}$ Instituto Agronômico do Paraná, Ponta Grossa, Paraná, Brasil.

${ }^{3}$ Universidade Federal do Paraná, Palotina, Paraná, Brasil.

*Endereço para correspondência: kfgobbi@iapar.br
}

\section{RESUMO}

Avaliou-se o desempenho e as características de carcaça de tourinhos mestiços confinados, alimentados com dieta contendo diferentes níveis de silagem de bagaço de laranja $(0,20$, 40 ou $60 \%$ ) substituindo a silagem de sorgo (\% da matéria seca). Foram utilizados 36 animais distribuídos em baias individuais, em um delineamento inteiramente casualizado com nove repetições. A ingestão de matéria seca (IMS) apresentou incremento quadrático $(\mathrm{P}<0,01)$ em função dos níveis de silagem de bagaço de laranja na dieta. O ganho médio diário (GMD) também teve comportamento quadrático $(\mathrm{P}<0,01)$ em função do incremento da silagem de bagaço de laranja, estimando-se que o nível que permite máximo GMD é de $24,50 \%$. Entretanto, ao se comparar as médias de GMD observou-se que a dieta com $20 \%$ de silagem de bagaço de laranja não diferiu das dietas com silagem de sorgo exclusiva e $40 \%$ de silagem de bagaço. A conversão alimentar não foi afetada pelas dietas $(\mathrm{P}>0,05)$, apresentando valor médio de 6,52. As características de carcaça não sofreram alterações $(\mathrm{P}>0,05) \mathrm{em}$ função dos tratamentos. Foram observados valores médios de 298,37 kg; 13,50; 135,14 cm; $26,35 \mathrm{~cm} ; 72,17 \mathrm{~cm}^{2} ; 5,26 \mathrm{~mm} ; 5,81 ; 64,54 \%$; $21,05 \% ; 15,09 \%$, para peso de carcaça quente, conformação, comprimento de carcaça, espessura de coxão, área de olho de lombo, espessura de gordura subcutânea, marmoreio e porcentagens de músculo, gordura e osso, respectivamente. A silagem de bagaço de laranja pode substituir a silagem de sorgo em até $40 \%$ da matéria seca, mas o nível de $24,5 \%$ é o que proporcionou máximo desempenho dos animais.

Palavras-chave: área de olho de lombo, conformação, espessura de gordura, ganho médio diário, marmoreio

\section{SUMMARY}

The study was conducted to evaluate the performance and carcass characteristics of crossbred young bulls in feedlot, fed rations with different levels of orange peel silage $(0$; $20 ; 40$ or $60 \%)$ replacing the sorghum silage (\% of dry matter). Thirty-six animals were allotted to individual pens, in a completely randomized design, with four treatments and nine replicates. The dry matter intake (DMI) showed a quadratic increase according to the level of orange peel silage in the diet. Average daily gain (ADG) was also quadratic behavior due to the increase of orange peel silage. It is estimated that level that allows maximum $\mathrm{ADG}$ is $24.50 \%$. However, the ADG of the animals receiving diets with $20 \%$ of orange peel silage did not differ from those receiving sorghum silage or $40 \%$ of orange peel silage. The feed conversion ratio was not significantly affected $(\mathrm{P}>0.05)$ by treatments, with an average value of 6.52. Carcass characteristics were not altered $(\mathrm{P}>0.05)$ by treatments. Average values of $298.37 \mathrm{~kg} ; 13.50 ; 135.14 \mathrm{~cm} ; 26.35 \mathrm{~cm} ; 72.17$ $\mathrm{cm}^{2} ; 5.26 \mathrm{~mm} ; 5.81 ; 64.54 \% ; 21.05 \% ; 15.09 \%$, 
were observed for hot carcass weight, carcass conformation, carcass length, cushion thickness, rib eye area, subcutaneous fat thickness, marbling, and muscle, fat and bone yield, respectively. Orange peel silage can replace up to $40 \%$ of sorghum silage dry matter, with the same daily gain and without affecting carcass characteristics.

Keywords: average daily gain, conformation, fat thickness, marbling, rib eye area

\section{INTRODUÇÃO}

Coprodutos resultantes de atividades agroindustriais e que podem ser utilizados na alimentação animal, têm potencial para manter e até aumentar os níveis de produção do rebanho. Além disso, podem contribuir para o aumento da eficiência dos sistemas de produção, caso promovam a redução dos custos.

No Brasil são colhidas anualmente mais de 18 milhões de toneladas de laranja e o país é responsável por cerca de $60 \%$ da produção mundial de suco de laranja (MAPA, 2014), sendo o Paraná o quinto maior produtor de laranja do Brasil, com cerca de 784.543 toneladas (IBGE, 2011), e a produção concentrada na região Noroeste do Estado. A indústria de suco de laranja produz como subproduto o bagaço de laranja, que compreende aproximadamente $42 \%$ do total do fruto (casca, sementes e porção tegumentar). Este resíduo, se não aproveitado, pode representar um problema sério de contaminação ambiental.

Adicionalmente, a colheita da laranja coincide com a época de escassez de forragem (inverno). Assim, um dos destinos que pode ser dado ao bagaço de laranja é seu uso na alimentação animal, principalmente de bovinos, podendo contribuir para redução dos custos de produção (BAMPIDIS \& ROBINSON, 2006) e eliminando resíduos com potencial de poluição ambiental (ÍTAVO et al., 2000a).
Uma das principais formas de utilização do bagaço ou polpa de laranja na alimentação de ruminantes é a polpa cítrica peletizada, obtida após secagem e prensagem dos resíduos da extração de suco. No entanto, devido ao elevado custo da secagem, há interesse das empresas em desenvolver mercados para o bagaço úmido de laranja (SANTOS et al., 2001).

O bagaço de laranja in natura é bem aceito pelos animais, porém o uso de grandes quantidades pode ter custo elevado em função do transporte e perdas causadas pela dificuldade de armazenamento, fermentação e proliferação de microrganismos indesejáveis (BAMPIDIS \& ROBINSON, 2006). Os altos teores de umidade e de açúcares tornam o bagaço de laranja um material bastante sensível à deterioração causada pelo desenvolvimento de fungos e leveduras (ASHBELL et al., 1988). Dessa forma, uma alternativa para a melhor preservação e uso do bagaço de laranja é a ensilagem, que permite a preservação do alimento por período prolongado.

Como os trabalhos de pesquisa avaliando o uso da silagem de bagaço de laranja na alimentação de bovinos ainda são escassos, realizou-se ensaio experimental para avaliar o desempenho e as características de carcaça de tourinhos mestiços alimentados com dieta contendo diferentes níveis de silagem de bagaço de laranja substituindo a silagem de sorgo.

\section{MATERIAL E MÉTODOS}

O experimento foi realizado no IAPAR, Estação Experimental de Paranavaí, na região Noroeste do estado do Paraná. Esta região apresenta clima $\mathrm{Cfa}$ (subtropical úmido), segundo classificação de Köeppen (IAPAR, 1978). 
O projeto de pesquisa foi aprovado pela Comissão de Ética no Uso de Animais (CEUA) do IAPAR, tendo sido realizado dentro das normas técnicas de biossegurança e ética.

Foram produzidas 200 toneladas de silagem de sorgo, sem aditivos e acondicionada em silo tipo trincheira, utilizando-se o sorgo forrageiro Volumax ${ }^{\circledR}$.Para confecção da silagem de bagaço de laranja foram utilizadas 150 toneladas de bagaço, provenientes da empresa COCAMAR de Paranavaí/PR. O bagaço foi ensilado no mês de julho, em silo tipo trincheira, com tampa frontal para contenção do bagaço, revestido com lona dupla face.As silagens de sorgo e de bagaço de laranja foram utilizadas após 60 e 30 dias de fermentação no silo, respectivamente.

Os tratamentos experimentais foram constituídos por quatro níveis de substituição da silagem de sorgo pela silagem de bagaço de laranja: 0, 20, 40 e $60 \%$ da matéria seca (MS).

$\mathrm{O}$ delineamento experimental utilizado foi o completamente casualizado, com quatro tratamentos e nove repetições, totalizando 36 unidades experimentais. Foram utilizados tourinhos mestiços oriundos de um projeto de avaliação de cruzamentos, com peso médio inicial de $396 \pm 54 \mathrm{~kg}$ e idade variando entre 20 e 22 meses. Utilizou-se animais dos seguintes grupos genéticos: Nelore; $1 / 2$ Limousin $+1 / 2$ Nelore; $1 / 2$ Limousin + 1/4 Red Angus + 1/4 Nelore; 2/3Red Angus + 1/3Nelore; 1/2Purunã + 1/4Red Angus $+1 / 4$ Nelore, distribuídos uniformemente entre os tratamentos.

O período experimental teve a duração de 84 dias, divididos em três períodos de 28 , sendo 21 dias de adaptação e sete de coleta, quando o alimento fornecido e as sobras eram pesados diariamente para determinação do consumo.
Os animais utilizados no experimento foram alocados em baias individuais, com acesso a cocho de alimentação e água. Os animais receberam as rações experimentais em mistura total ad libitum, duas vezes ao dia (9:00 e 16:00 horas), em quantidade suficiente para permitir cerca de $10 \%$ de sobras.

A quantidade de concentrado (1\%) foi calculada com base no peso corporal (PC), sendo reajustada a cada 28 dias, após a pesagem dos animais. $\mathrm{O}$ concentrado foi formulado utilizando-se farelo de soja, milho, uréia, calcário e sal mineral, e as dietas calculadas para que tivessem em torno de $12 \%$ de proteína bruta e $70 \%$ de nutrientes digestíveis totais (NDT).

As amostras compostas das dietas totais, das silagens e do concentrado foram secas em estufa com ventilação forçada a $55^{\circ} \mathrm{C}$ por 72 horas e moídas em moinho tipo Wiley, utilizando-se peneira com malha de $1 \mathrm{~mm}$. As amostras foram analisadas quanto aos teores de matéria seca (MS), proteína bruta (PB), fibra em detergente neutro (FDN), fibra em detergente ácido (FDA), celulose, hemicelulose e lignina (SILVA \& QUEIROZ, 2002).

Para avaliação do ganho médio diário (GMD) os animas foram pesados, após jejum de 12 horas (sólidos e líquidos), no início e no final de cada período experimental (28 dias).

$\mathrm{O}$ abate dos animais foi realizado de acordo com a rotina de frigorífico comercial. Os mesmos foram insensibilizados por meio de concussão cerebral (pistola pneumática), seguido do abate pela secção da veia jugular (BRASIL, 2000). Após abate, as meiascarcaças foram identificadas, pesadas, para avaliação do peso de carcaça quente, e acondicionadas em câmara fria mantida à temperatura de $2^{\circ} \mathrm{C}$, por um período de 24 horas, para posterior avaliação das seguintes características de carcaça: conformação, comprimento, espessura de coxão, área de olho de 
Rev. Bras. Saúde Prod. Anim., Salvador, v.15, n.4, p.917-927 out./dez., 2014 http://www.rbspa.ufba.br ISSN 15199940

lombo, espessura de gordura de cobertura e percentagem de osso, músculo e gordura.

$\mathrm{O}$ peso de carcaça quente foi determinado pelo peso das duas meiascarcaças em kg, logo após o abate, antes de entrarem na câmara de resfriamento.

A conformação baseia-se em uma avaliação subjetiva, segundo metodologia descrita por Müller (1987), onde os valores mais elevados correspondem à melhor conformação.

O comprimento, que compreende a distância entre o bordo anterior do osso púbis e o bordo crânio-medial da primeira costela, foi medido com uma trena.

A espessura de coxão foi mensurada com o auxílio de um compasso de madeira, medindo-se a distância entre a face lateral e medial da porção superior do coxão.

Para avaliação da área de olho de lombo e espessura de gordura subcutânea foi feito um corte horizontal entre a $12^{\mathrm{a}}$ e a $13^{\mathrm{a}}$ costela com o objetivo de expor o músculo Longissimus, aferindo-se a área do músculo com auxílio de um planímetro. A espessura de gordura subcutânea foi obtida pela média aritmética de três observações na parte cranial, medial e final do músculo, utilizando-se paquímetro. A quantidade de gordura intramuscular (marmoreio) foi avaliada após exposição do músculo Longissimus ao ar por 30 minutos (MÜLLER, 1980).

Para determinação da composição física da carcaça em músculo, gordura e osso, foi extraída uma peça correspondendo a 10,11 e $12^{\mathrm{a}}$ costelas, segundo a metodologia proposta por Hankins \& Howe (1946), adaptada por Müller (1987).

A análise estatística dos dados foi realizada utilizando-se o procedimento GLM (General Linear Models) e REG do pacote estatístico SAS (SAS Institute, 1999). As médias foram comparadas utilizando-se o recurso
LSMEANS. Em todas as análises adotou-se o nível de significância de $5 \%$.

\section{RESULTADOS E DISCUSSÃO}

A composição químico-bromatológica do concentrado, da silagem de sorgo e de bagaço de laranja, bem como das misturas utilizadas nas dietas encontrase na Tabela 1. A composição da silagem de bagaço de laranja apresentou valores condizentes com o encontrado por outros autores (ÍTAVO et al., 2000a; REGO et al., 2012; VILLANUEVA et al. 2013), com algumas variações, que de acordo com Ammerman \& Henry (1991), podem ser atribuídas aos diferentes processos de extração do suco, procedência e variedade dos frutos.

A ingestão de matéria seca (IMS) em $\mathrm{kg} / \mathrm{dia}$ foi afetada de forma significativa pelos tratamentos, apresentando comportamento quadrático $(\mathrm{P}<0,01)$ em função do aumento da quantidade de silagem de bagaço de laranja nas dietas experimentais (Tabela 2). Estimou-se ingestão máxima de MS para o nível de $21,60 \%$ de silagem de bagaço, conforme equação de regressão (Figura 1). Da mesma forma a IMS em porcentagem do peso corporal também aumentou de forma quadrática $(\mathrm{P}<0,001)$ em função dos níveis crescentes de silagem de bagaço de laranja, observando-se máxima IMS (\%PC) para o nível de $28,75 \%$ de silagem de bagaço de laranja (Figura 2). A conversão alimentar não foi afetada de forma significativa $(\mathrm{P}>0,05)$ pelos tratamentos, apresentando um valor médio de 6,52 (Tabela 2). O ganho médio diário (GMD) dos animais apresentou comportamento quadrático $(\mathrm{P}<0,01)$ em função do incremento da silagem de bagaço de laranja (Figura 3), estimando-se que o nível de $24,50 \%$ de 
Rev. Bras. Saúde Prod. Anim., Salvador, v.15, n.4, p.917-927 out./dez., 2014 http://www.rbspa.ufba.br ISSN 15199940

silagem de bagaço de laranja permite máximo GMD.

Por outro lado, quando foram comparadas as médias do GMD, observou-se que os animais recebendo a dieta com $20 \%$ de silagem de bagaço de laranja não diferiram estatisticamente dos animais alimentados com silagem de sorgo e $40 \%$ de silagem de bagaço. Da mesma forma que a IMS, tanto em $\mathrm{kg}$ por dia quanto em porcentagem do peso corporal, foi menor para os animais que receberam a dieta com $60 \%$ de silagem de bagaço de laranja substituindo a silagem de sorgo, mas não diferiu entre os demais tratamentos (Tabela 2).

Os valores máximos de substituição do volumoso por silagem de bagaço de laranja foram inferiores aos observados por Pereira et al. (2008). Estes autores avaliaram a substituição de silagem de milho por polpa cítrica úmida $(0 ; 25 ; 50$ ou $75 \%)$ na dieta de cordeiros. Eles observaram diferença para ingestão de matéria seca e conversão alimentar, mas o ganho de peso médio apresentou comportamento quadrático em função do aumento dos níveis de polpa cítrica úmida, e o nível de substituição de $48 \%$ promoveu o maior ganho médio diário.

Tabela 1. Composição químico-bromatológica do concentrado, da silagem de sorgo e de bagaço de laranja, e das misturas de silagem de sorgo/silagem de bagaço de laranja utilizadas nas dietas experimentais

\begin{tabular}{lcccccc}
\hline \multirow{2}{*}{ Variáveis } & \multicolumn{7}{c}{ Alimentos } \\
\cline { 2 - 6 } & SB & SS & SB 20 & SB 40 & SB 60 & Concentrado \\
\hline MS (\%) & 16,18 & 35,25 & 29,97 & 24,51 & 20,56 & 90,01 \\
PB* $^{*}$ & 6,34 & 4,98 & 5,23 & 5,33 & 6,30 & 11,55 \\
FDN* & 28,35 & 62,39 & 56,93 & 47,02 & 31,29 & 19,55 \\
FDA* & 32,00 & 41,50 & 40,46 & 35,32 & 35,14 & 7,61 \\
Hemicelulose* & 5,97 & 21,68 & 17,71 & 13,78 & 13,02 & 13,61 \\
Celulose* & 27,27 & 33,16 & 32,53 & 30,29 & 30,08 & 5,30 \\
Lignina* & 4,74 & 8,33 & 7,93 & 5,03 & 5,05 & 2,31 \\
\hline
\end{tabular}

SS = silagem de sorgo; SB $20=20 \%$ de silagem de bagaço de laranja; SB $40=40 \%$ de silagem de bagaço de laranja; SB $60=60 \%$ de silagem de bagaço de laranja.

*Porcentagem da Matéria Seca.

Tabela 2. Ingestão de matéria seca (IMS), ganho médio diário (GMD) e conversão alimentar (CA) de tourinhos mestiços alimentados com rações contendo silagem de bagaço de laranja substituindo a silagem de sorgo

\begin{tabular}{|c|c|c|c|c|c|}
\hline \multirow{2}{*}{ Variáveis } & \multicolumn{4}{|c|}{ Tratamentos } & \multirow{2}{*}{$\mathrm{CV}(\%)$} \\
\hline & SS & SB 20 & SB 40 & SB 60 & \\
\hline IMS (kg/dia) & $10,05^{\mathrm{a}}$ & $10,73^{\mathrm{a}}$ & $10,30^{\mathrm{a}}$ & $8,37^{\mathrm{b}}$ & 12,70 \\
\hline IMS (\% PC) & $2,06^{\mathrm{a}}$ & $2,19^{\mathrm{a}}$ & $2,13^{\mathrm{a}}$ & $1,84^{\mathrm{b}}$ & 5,69 \\
\hline GMD (kg/dia) & $1,57^{\mathrm{ab}}$ & $1,71^{\mathrm{a}}$ & $1,52^{\mathrm{ab}}$ & $1,33^{\mathrm{b}}$ & 12,61 \\
\hline $\mathrm{CA}$ & 6,42 & 6,32 & 6,97 & 6,40 & 12,81 \\
\hline
\end{tabular}

Médias seguidas de letras diferentes, na mesma linha, são estatisticamente diferentes $(\mathrm{P}<0,05)$ pelo teste de Tukey.

SS = silagem de sorgo; SB $20=20 \%$ de silagem de bagaço de laranja; $\mathrm{SB} 40=40 \%$ de silagem de bagaço de laranja; SB $60=60 \%$ de silagem de bagaço de laranja. 
Rev. Bras. Saúde Prod. Anim., Salvador, v.15, n.4, p.917-927 out./dez., 2014 http://www.rbspa.ufba.br ISSN 15199940

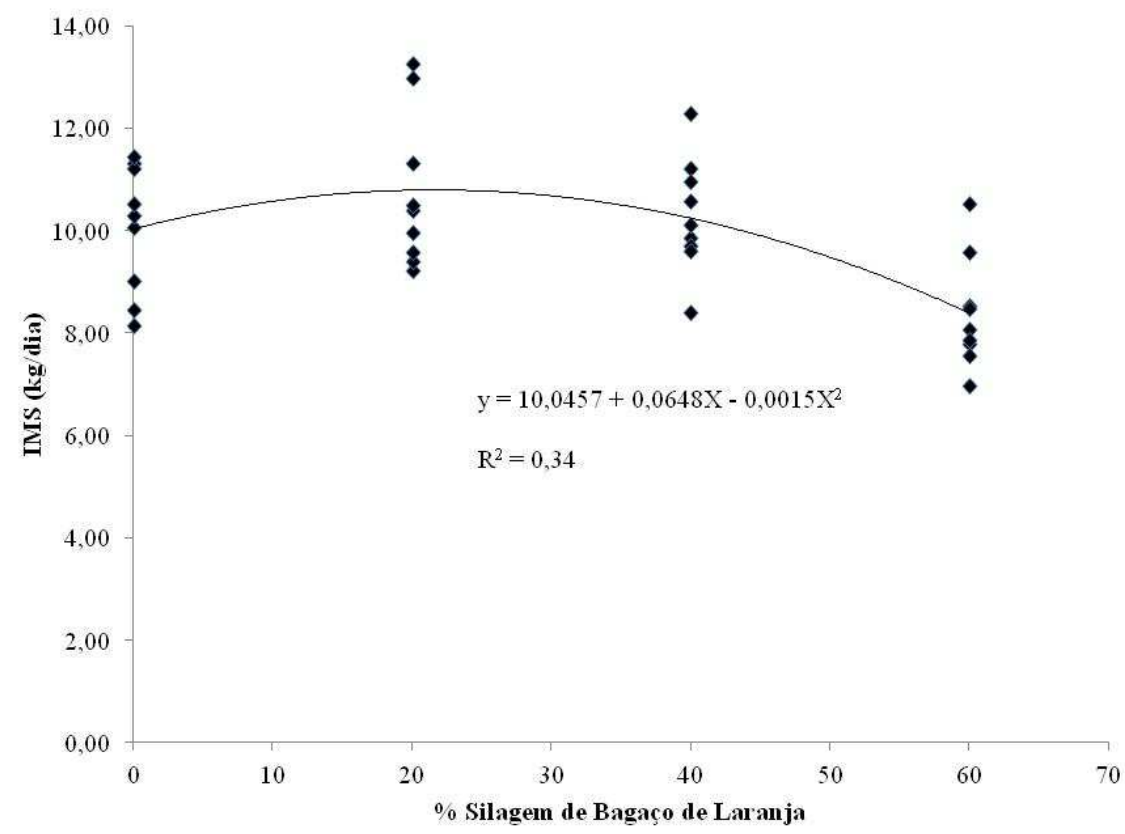

Figura 1. Ingestão de matéria seca (kg/dia) em função dos níveis de silagem de bagaço de laranja substituíndo a silagem de sorgo na dieta

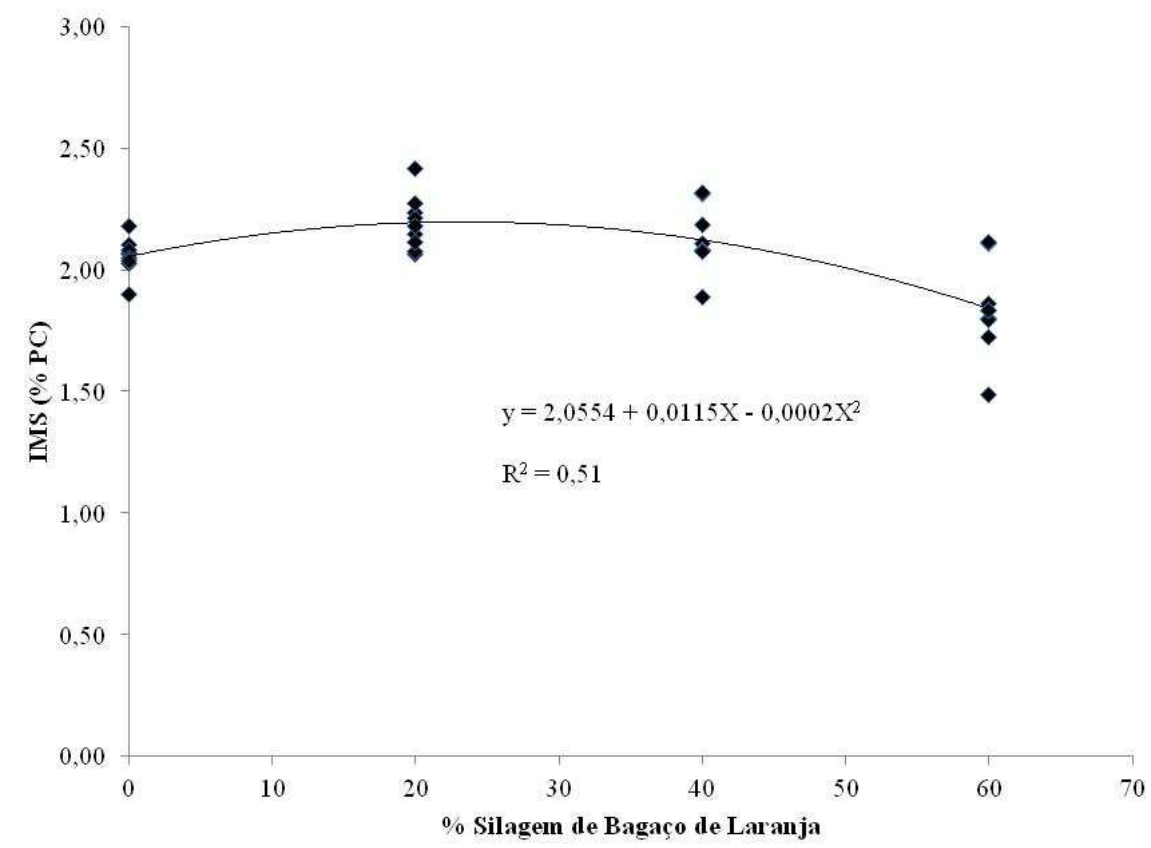

Figura 2. Ingestão de matéria seca (\%Peso Corporal) em função dos níveis de silagem de bagaço de laranja substituíndo a silagem de sorgo na dieta 


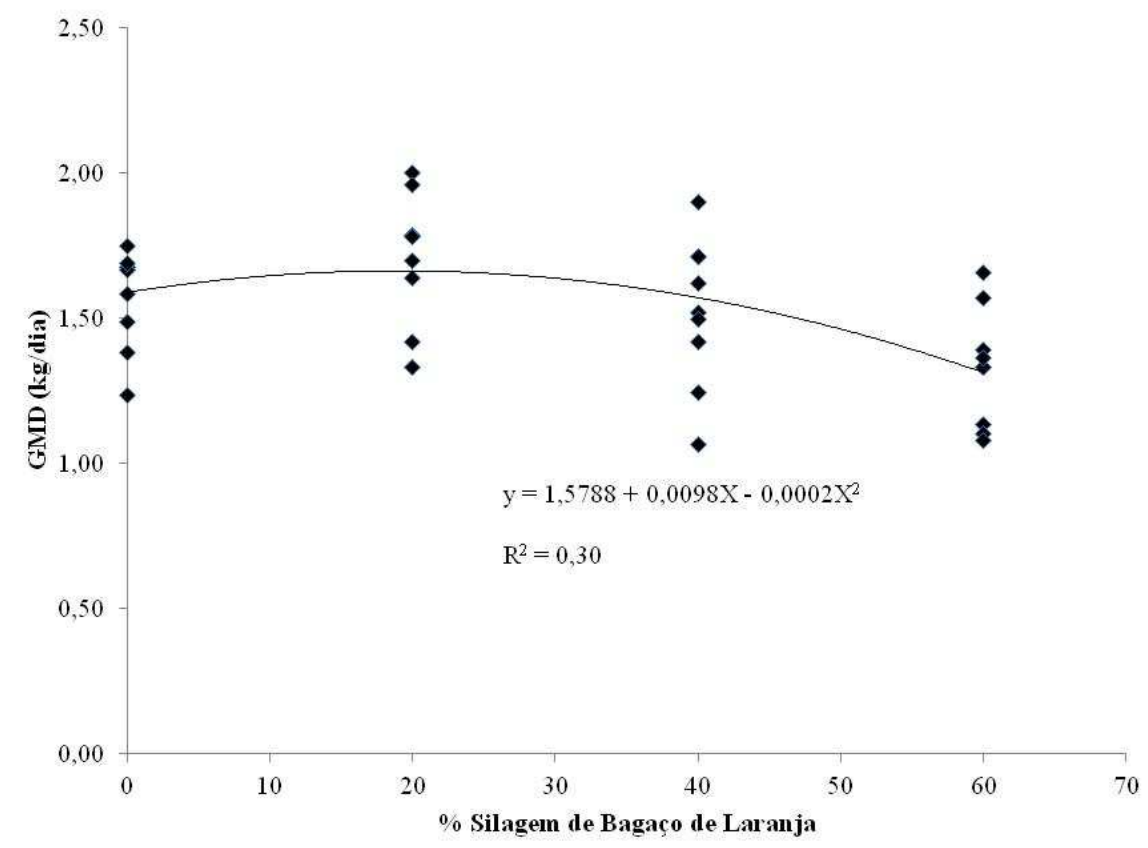

Figura 3. Ganho médio diário ( $\mathrm{kg} / \mathrm{dia}$ ) em função dos níveis de silagem de bagaço de laranja substituíndo a silagem de sorgo na dieta

O uso do bagaço de laranja para substituir parte do volumoso e até mesmo dos grãos na dieta de bovinos de corte confinados pode representar uma alternativa de redução dos custos. Particularmente nas regiões produtoras de laranja as indústrias de suco disponibilizam o bagaço a preços acessíveis, muitas vezes cobrando apenas o frete para o transporte até a propriedade.

Villanueva et al. (2013) avaliaram o desempenho de ovinos consumindo bagaço de laranja fresco em substituição ao grão de sorgo nas dietas. Os autores concluíram que o bagaço de laranja pode substituir até $30 \%$ dos grãos de sorgo na dieta, sem diminuir a produtividade dos animais, além de representar uma redução de $48 \%$ no custo da alimentação por $\mathrm{kg}$ de animal produzido.

A tendência de melhora do desempenho dos animais alimentados com o bagaço de laranja, em parte, pode ser explicada pela maior eficiência da utilização dos alimentos da dieta. De acordo com Martins et al. (1999) a degradabilidade ruminal do farelo de soja fica em torno de $74,1 \%$ e da silagem de sorgo em torno de $46 \%$. Por sua vez, a degradabilidade da silagem de bagaço de laranja pode superar os $90 \%$ (ÍTAVO et al., 2000b). Segundo o NRC (2001), a sincronização entre a disponibilização de nitrogênio e energia no rúmen possibilita uma maior produção de proteína microbiana, melhorando o aporte de aminoácidos microbianos no duodeno e assim, possibilitando a melhora no desempenho animal.

A queda na ingestão de MS, bem como a redução do GMD para os animais que receberam a dieta com maiores níveis de silagem de bagaço de laranja (60\%) pode estar relacionada com a menor aceitabilidade dos animais aos altos níveis de bagaço. Esta redução na ingestão de MS também foi observada por outros autores (HENRIQUE et al., 
1998; ÍTAVO et al., 2000a; PEREIRA et al., 2008; VILLANUEVA, et al. 2013).

Scerra et al. (2001) avaliaram o desempenho e as características de carcaça de cordeiros alimentados com feno de aveia + concentrado ou silagem de polpa cítrica fresca $(80 \%$ polpa fresca $+20 \%$ palha de trigo picada $)+$ concentrado. Os autores não observaram efeito da dieta sobre o ganho de peso diário dos animais, mas a conformação da carcaça foi melhor nos animais recebendo a dieta com silagem de polpa cítrica. Os animais recebendo silagem também apresentaram menor proporção de gordura na carcaça.

No presente estudo as características de carcaça avaliadas não sofreram alterações $(\mathrm{P}>0,05)$ em função dos níveis de silagem de bagaço de laranja substituindo a silagem de sorgo nas dietas (Tabela 3).

Tabela 3. Características de carcaça de tourinhos alimentados com rações contendo silagem de bagaço de laranja substituindo a silagem de sorgo

\begin{tabular}{lccccc}
\hline \multirow{2}{*}{ Variáveis } & \multicolumn{4}{c}{ Tratamentos } & \multirow{2}{*}{ CV (\%) } \\
\cline { 2 - 5 } Peso de carcaça quente $(\mathrm{kg})$ & $\mathrm{SS}$ & $\mathrm{SB} 20$ & $\mathrm{SB} 40$ & $\mathrm{SB} 60$ & 13,38 \\
Conformação carcaça & 296,20 & 305,82 & 304,60 & 286,87 & 15,22 \\
Comprimento carcaça & 13,44 & 14,00 & 13,78 & 12,78 & 15,00 \\
Espessura coxão (cm) & 137,61 & 134,11 & 134,62 & 134,22 & 3,60 \\
Área de olho de lombo $\left(\mathrm{cm}^{2}\right)$ & 26,06 & 26,56 & 26,17 & 26,61 & 8,45 \\
Espessura gordura de subcutânea (mm) & 70,78 & 73,33 & 72,22 & 72,33 & 10,82 \\
Marmoreio & 4,33 & 5,33 & 6,17 & 5,22 & 28,11 \\
Músculo (\%) & 4,89 & 6,11 & 6,00 & 6,22 & 27,72 \\
Gordura (\%) & 65,21 & 64,40 & 64,37 & 64,16 & 3,41 \\
Osso (\%) & 20,16 & 21,12 & 21,46 & 21,47 & 11,13 \\
\hline
\end{tabular}

SS = silagem de sorgo; SB $20=20 \%$ de silagem de bagaço de laranja; SB $40=40 \%$ de silagem de bagaço de laranja; SB $60=60 \%$ de silagem de bagaço de laranja.

O peso da carcaça quente apresentou valor médio de 298,37 kg. Apesar de não haver diferença estatística entre os tratamentos, observou-se tendência de maior peso das carcaças para os animais recebendo dietas com 20 e $40 \%$ de silagem de bagaço de laranja, o que corrobora o melhor desempenho dos animais recebendo estas dietas. Considerando que o peso de carcaça é um dos fatores que mais afeta a comercialização entre pecuaristas e frigoríficos (PASCOAL et al. 2011), pode-se considerar que os valores obtidos neste ensaio atendem os padrões exigidos pelo mercado, superando o limite mínimo exigido $(230 \mathrm{~kg}$ ou 15
@), evitando-se a penalização no valor pago pelo frigorífico.

A conformação média das carcaças $(13,50)$ permite classificá-las entre muito boas - e muito boas médias. De acordo com Müller (1987), é desejável que as carcaças apresentem melhor conformação, pois de modo geral estas apresentam melhor aspecto visual, com maior hipertrofia muscular, atendendo a preferência de açougues e consumidores, bem como menor proporção de osso e maior porção comestível.

Assim como o peso médio da carcaça quente $(298,37 \mathrm{~kg})$, a espessura de coxão $(26,35 \mathrm{~cm})$ e área de olho de lombo $\left(72,17 \mathrm{~cm}^{2}\right)$, que expressam a 
musculosidade da carcaça, não apresentaram variação em função dos tratamentos (Tabela 3).

A espessura de gordura subcutânea, que variou de 4,33 a 6,17 , se enquadra na faixa exigida pelos frigoríficos, de 3 a 6 mm (COSTA et al., 2002). A espessura de gordura inferior a $3 \mathrm{~mm}$ pode reduzir o valor pago ao produtor, uma vez que pode contribuir para o resfriamento mais rápido da carne, com redução da maciez e escurecimento da parte externa dos músculos que recobrem a carcaça. Já quando a cobertura de gordura supera os $6 \mathrm{~mm}$ serão feitos recortes para eliminação do excesso de gordura antes da pesagem da carcaça, com maior custo operacional para o frigorífico e prejuízo para o produtor.

Pode-se observar a tendência de maior espessura de gordura para os animais recebendo dietas com silagem de bagaço de laranja. Isto pode estar relacionado ao fato de o bagaço de laranja possuir elevado conteúdo de fibras solúveis e pectina que propiciam um padrão de fermentação com maior produção de ácido acético (WING, 1982), e de acordo com Smith e Crouse (1984) o acetato é o substrato primário para deposição de gordura subcutânea.

O marmoreio, que expressa a gordura intramuscular, com valor médio de 5,81, foi classificado como leve médio a leve +. Como animais não castrados depositam menos gordura intramuscular, os valores observados são considerados razoáveis.

As porcentagens médias de músculo $(64,54 \%)$, gordura $(21,05 \%)$ e osso $(15,09 \%)$ são compatíveis com animais jovens não castrados (Tabela 3 ).

O melhor desempenho dos animais foi alcançado quando a silagem de bagaço de laranja substituiu $24,5 \%$ da silagem de sorgo na dieta de tourinhos confinados. Entretanto, a silagem de bagaço de laranja pode substituir a silagem de sorgo em até 40\% (MS), com ganhos de peso e características de carcaça semelhantes entre os animais.

\section{AGRADECIMENTOS}

À empresa COCAMAR, de Paranavaí/PR, pelo fornecimento do bagaço de laranja utilizado no ensaio experimental.

\section{REFERÊNCIAS}

AMMERMAN, C.B.; HENRY, P.R. Citrus and vegetable products for ruminants animals: feeding and Nutrition. Gainesville: University of Florida, 1991.

ASHBELL, G.; WEINBERG, Z.G.; ARIELI, A. Effect of blanching and loss reduction in orange peel storage.

Journal of the Science of Food and Agriculture, v.45, p.196-201, 1988.

BAMPIDIS, V.A.; ROBINSON, P.H. Citrus by-products as ruminant feeds: a review. Animal Feed Science and Technology, v.128, p.175-217, 2006.

BRASIL. Ministério da Agricultura. Instrução Normativa $n^{\circ} 3$ de 17 de jan. de 2000. Regulamento técnico de métodos de insensibilização para o abate humanitário de animais de açougue. Diário Oficial da União, Brasília, 24 jan. 2000.

COSTA, E.C.; RESTLE, J.; VAZ, F.N. ALVES FILHO, D.C.; BERNARDES, R.A.L.; KUSS, F. Características da carcaça de novilhos Red Angus superprecoces abatidos com diferentes pesos. Revista Brasileira de

Zootecnia, v.31, n.1, p.119-128, 2002. 
HANKINS, O.G.; HOWE, P.E.

Estimation of the composition of beef carcass and cuts. Technical Bulletin, n.926, p.1-20, 1946.

HENRIQUE, W.; LEME, P.R.; LANNA, D.P.D.; COUTINHO FILHO, J.L.V.; PERES, R.M.; JUSTO, C.L.; SIQUEIRA, P.A.; ALLEONI, G.F. Substituição de amido por pectina em dietas com diferentes níveis de concentrado. Desempenho animal e características de carcaça. Revista Brasileira de

Zootecnia, v.27, n.6, p.1206-1211, 1998.

INSTITUTO AGRONÔMICO DO PARANÁ - IAPAR. Cartas climáticas básicas do estado do Paraná. Londrina, 1978. 41p.

INSTITUTO BRASILEIRO DE GEOGRAFIA E ESTATÍSTICA IBGE. Levantamento sistemático da produção agrícola: pesquisa mensal de previsão e acompanhamento das safras agrícolas no ano civil. 2011. v.22, n.2, p.1-80.

ÍTAVO, L.C.V.; SANTOS, G.T.; JOBIM, C.C.; VOLTOLINI, T.V.; FARIA, K.P.; FERREIRA, C.C.B. Substituição da silagem de milho pela silagem do bagaço de laranja na alimentação de vacas leiteira. Consumo, Produção e Qualidade do leite. Revista Brasileira de Zootecnia, v.29, n.5, p.1498-1503, 2000a.

ÍTAVO, L.C.V.; SANTOS, G.T.; JOBIM, C.C.; VOLTOLINI, T.V.; FERREIRA, C.C.B. Degradabilidade das silagens de bagaço de laranja e de milho. In: REUNIÃO ANUAL DA SOCIEDADE BRASILEIRA DE ZOOTECNIA, 37., 2000, Viçosa. Anais... Viçosa: Sociedade Brasileira de Zootecnia, 2000b. p.376.
MINISTÉRIO DA AGRICULTURA, PECUÁRIA E ABASTECIMENTO MAPA. Citrus. 2014. Disponível em: <http://www.agricultura.gov.br/vegetal/ culturas/citrus.html> . Acesso em: 24 mar. 2014.

MARTINS, A.S.; ZEOULA, L.M.; PRADO, I.N.; MARTINS, E.N.; LOYOLA, V.R. Degradabilidade ruminal in situ da matéria seca e proteína bruta das silagens de milho e sorgo e de alguns alimentos concentrados. Revista Brasileira de Zootecnia, v.28, n.5, p.1109-1117, 1999.

MÜLLER, L. Normas para avaliação de carcaças e concurso de carcaças de novilhos. 2.ed. Santa Maria: Imprensa Universitária, 1987. 31p.

NATIONAL RESEARCH COUNCIL NRC. Nutrient requeriments of dairy cattle. 7.rev.ed. Washinton, D.C., 2001. $381 \mathrm{p}$.

PASCOAL, L.L.; VAZ, F.N.; VAZ, R.Z.; RESTLE, J.; PACHECO, P.S.;

SANTOS, J.P.A. Relações comerciais entre produtor, indústria e varejo e as implicações na diferenciação e precificação da carne e produtos bovinos não-carcaça. Revista Brasileira de Zootecnia, v.40, p.82-92, 2011.

PEREIRA, M.S.; RIBEIRO, E.L.A.; MIZUBUTI, I.Y.; ROCHA, M.A.; KURAOKA, J.T.; NAKAGHI, E.Y.O. Consumo de nutrientes e desempenho de cordeiros em confinamento alimentados com dietas com polpa cítrica úmida prensada em substituição à silagem de milho. Revista Brasileira de Zootecnia, v.37, n.1, p.134-139, 2008. 
REGO, F.C.A.; LUDOVICO, A.; SILVA, L.C.; LIMA, L.D.; SANTANA, E.W.; FRANÇOZO, M.C. Perfil fermentativo, composição bromatológica e perdas em silagem de bagaço de laranja com diferentes inoculantes microbianos. Semina:

Ciências Agrárias, v.33, p.3411-3420, 2012.

SANTOS, G.T.; ÍTAVO, L.C.V.; MODESTO, E.C.; JOBIM, C.C.; DAMASCENO, J.C. Silagens alternativas de resíduos agroindustriais. In: SIMPÓSIO SOBRE PRODUÇÃO E UTILIZAÇÃO DE FORRAGENS CONSERVADAS, 2001, Maringá. Anais...Maringá, 2001. p.262-285.

SCERRA, V.; CAPARRA, P.; FOTI, F.; LANZA, M.; PRIOLO, A. Citrus pulp and wheat straw silage as an ingredient in lamb diets: effects on growth and carcass and meat quality. Small

Ruminant Research, v.40, p.51-56, 2001.

SILVA, D.J.; QUEIROZ, A.C. Análise de alimentos: métodos químicos e biológicos. Viçosa, MG: Universidade Federal de Viçosa, 2002. 165p.
SMITH, S.B.; CROUSE, D.J. Relative contributions of acetate, lactate and glucose to lipogenesis in bovine intramuscular and subcutaneous adipose tissue. The Journal of Nutrition, v.114, p.792-800, 1984.

SAS Institute. SAS user's guide: statistics. Cary, 1999. 965p.

VILLANUEVA, Z.; IBARRA, M.A.; ZÁRATE, P.; BRIONES, F.; ESCAMILLA, O.S.; GONZÁLES, A.; GUTIÉRREZ, E. Productive performance of hair lambs fed fresh Orange (Citrus sinensis) residues substituting sorghum (Sorghum vulgare) grains. Cuban Journal of Agricultural Science, v.47, n.1, p.27-31, 2013.

WING, J.M. Citrus feedstuffs for dairy cattle. Gainesville: University of Florida, Agricultural Experiment Station, 1982, 25p. (Bulletin, 829).

Data de recebimento: 29/04/2014 Data de aprovação: 30/10/2014 